\title{
Observations of the first meteorological rocket of the Meridian Space Weather Monitoring Project
}

\author{
JIANG GuoYing $^{1 *}$, XU JiYao ${ }^{1}$, SHI DongBo ${ }^{2}$, WEI Feng ${ }^{2} \&$ WANG LianZhong ${ }^{2}$ \\ ${ }^{1}$ State Key Laboratory of Space Weather, Center for Space Science and Applied Research, Chinese Academy of Sciences, Beijing 100190, China; \\ ${ }^{2}$ Rocket and Balloon Sounding, Center for Space Science and Applied Research, Chinese Academy of Sciences, Beijing 100190, China
}

Received January 27, 2011; accepted April 6, 2011

\begin{abstract}
On June 3, 2010, the first meteorological rocket of the Meridian Space Weather Monitoring Project was successfully launched at the Hainan rocket launch site $\left(19.5^{\circ} \mathrm{N}\right)$, China. This paper analyzes the vertical profiles of atmospheric temperature and wind recorded by the rocket and its supportive balloons, and investigates wind shear, gravity waves and atmospheric stability. In addition, we compare the vertical profiles of atmospheric temperature and wind with SABER/TIMED temperature measurements and the modeling results of MSISO0 and HWM07.
\end{abstract}

Meridian Space Weather Monitoring Project, meteorological rocket, atmospheric temperature, wind shear, atmospheric stability

Citation: Jiang G Y, Xu J Y, Shi D B, et al. Observations of the first meteorological rocket of the Meridian Space Weather Monitoring Project. Chinese Sci Bull, 2011, 56: 2131-2137, doi: 10.1007/s11434-011-4537-5

We still have little understanding of the atmosphere at altitudes of $30-80 \mathrm{~km}$ because of the limited detection technology available, despite the importance of this height region to the launch and operation of aircraft. Observations of the $30-80 \mathrm{~km}$ atmosphere are required for aircraft manufacturing and study of the middle atmosphere. Meteorological rockets are an important means of obtaining information on atmospheric variables of the stratosphere and mesosphere (generally between 20 and $90 \mathrm{~km}$ ) [1-4].

On June 3, 2010, the first meteorological rocket of the Meridian Space Weather Monitoring Project (a large Chinese space environment observation system located along a longitude of 120 degrees east) was successfully launched at the Hainan rocket launch site, China. The rocket incorporated high-precision global positioning system technology. The rocket recorded data on atmospheric temperature, pressure and wind field parameters from the ground to a height of $60 \mathrm{~km}$. To support the adjustment of the rocket's launch angle, launch direction and trajectory, three balloons were released to obtain information of the atmospheric wind

*Corresponding author (email: gyjiang@ spaceweather.ac.cn) speed, wind direction, temperature and humidity; two were released before the rocket launch and one after.

A meteorological rocket has high time and altitude resolution, but its detection period is short. Therefore, the data from a single rocket are usually used to study small-scale atmospheric structures and short-period waves, such as wind shear, turbulence and gravity waves [1]. A network of rockets can investigate variations in these structures and waves with time and space [3-7].

In the present paper, we analyze data recorded by the first meteorological rocket of the Meridian Space Weather Monitoring Project. We present the atmospheric temperature and wind $(0-50 \mathrm{~km})$ recorded by the rocket and balloons and compare with temperature and wind data derived from satellite observations and modeling. Additionally, we study the wind shear and the vertical spectrum of gravity waves, and investigate atmospheric stability.

\section{Data and models}

The first meteorological rocket of the Meridian Space 
Weather Monitoring Project carried an advanced near-Earth space atmosphere detector developed by the Center for Space Science and Applied Research. This detector provides measurements of atmospheric parameters with high resolution. The rocket was launched at 04:00 on June 3, 2011. After $113 \mathrm{~s}$, the rocket reached the top of its trajectory and the detector separated from the rocket. Raw data on atmospheric parameters were continuously sent back during the descent, and the detector reached the ground after approximately 2.5 hours. The rocket data for wind and temperature collected at altitudes from 0 to $52 \mathrm{~km}$ are used in this paper.

The TIMED (Thermosphere-Ionosphere-Mesosphere Energetics and Dynamics) spacecraft was launched on December 7, 2001. The TIMED mission investigated the effects of the Sun and humans on the least explored and understood region of the Earth's atmosphere-the mesosphere and lower thermosphere/ionosphere. The SABER (Sounding of the Atmosphere using Broadband Emission Radiometry) instrument aboard the TIMED satellite was designed to measure the vertical distribution of infrared radiation emitted by various atmospheric gases (ozone, water vapor, nitrogen, and carbon dioxide) and the temperature and chemical structure of the atmosphere. The temperature data recorded by SABER have been used in many previous studies of the mesosphere and lower thermosphere and found to be reliable [8-13]. The SABER temperature data for the area of the rocket launch site $\left(19.5^{\circ} \pm 5^{\circ} \mathrm{N}, 109^{\circ} \pm 5^{\circ} \mathrm{E}\right)$ are used to verify the temperature observations made by the rocket and balloons, and satellite data for altitudes of 20 to $55 \mathrm{~km}$ are taken.

The primary version of the Mass Spectrometer and Incoherent Scatter (MSIS) empirical model was based on temperature, density, and composition data recorded by satellites and derived from incoherent scatter radar. Several upgrades have been released, with the latest version being MSIS00 [14]. The MSIS model provides the neutral temperature and density of the Earth's atmosphere from the ground to the thermosphere.

The primary version of the Horizontal Neutral Wind Model (HWM) was based on wind data recorded by the AE-E and DE 2 satellites. The HWM is an empirical model of the horizontal neutral wind in the upper thermosphere, and its latest version is HWM07 [15]. HWM07 provides a statistical representation of the horizontal wind fields of the Earth's atmosphere from the ground to the exosphere.

In this paper, the wind from HWM07 and temperature from MSIS00 are compared with the observations made by the rocket and balloons. We determine whether the model result is generally a result in the averaged sense.

Furthermore, the wind data recorded by the rocket are used to study wind shear, the vertical spectrum of gravity waves and atmospheric stability. The analysis method is presented in the third section of this paper.

Note that positive wind directions are eastward or north- ward and negative winds are westward or southward in this paper.

\section{Results}

\subsection{Temperature and wind recorded by the rocket and balloons}

Figure 1 shows the temperature features observed by the rocket, balloons and SABER/TIMED. The measurement periods are as follows. The rocket recorded data from 04:04:02 to $06: 30: 57$, the first balloon from $00: 42: 07$ to $01: 53: 37$, the second balloon from $02: 12: 17$ to $03: 22: 28$, and the third balloon from $06: 29: 34$ to $08: 08: 45$; SABER measurements around the rocket launch site and within the 22-55 km height range were made from 06:58:39 to 07:03:34. The data in Figure 1 are for a median time; for example, the median time for the rocket is $05: 16: 48$ and the median time for SABER is $07: 01: 12$.

Figure 1 shows that rocket and balloons both estimate the altitude of the tropopause to be about $17 \mathrm{~km}$, even though the detection periods differ. The time difference between the rocket and SABER observations is $2.5-3 \mathrm{~h}$, yet their temperature variations with altitude are similar, and only in the two height ranges of $24-30 \mathrm{~km}$ and $39-52 \mathrm{~km}$ are there distinct temperature differences. We also compare the balloon and SABER measurements in Figure 1. The third balloon lagged the SABER observations by $0.5 \mathrm{~h}$, which is

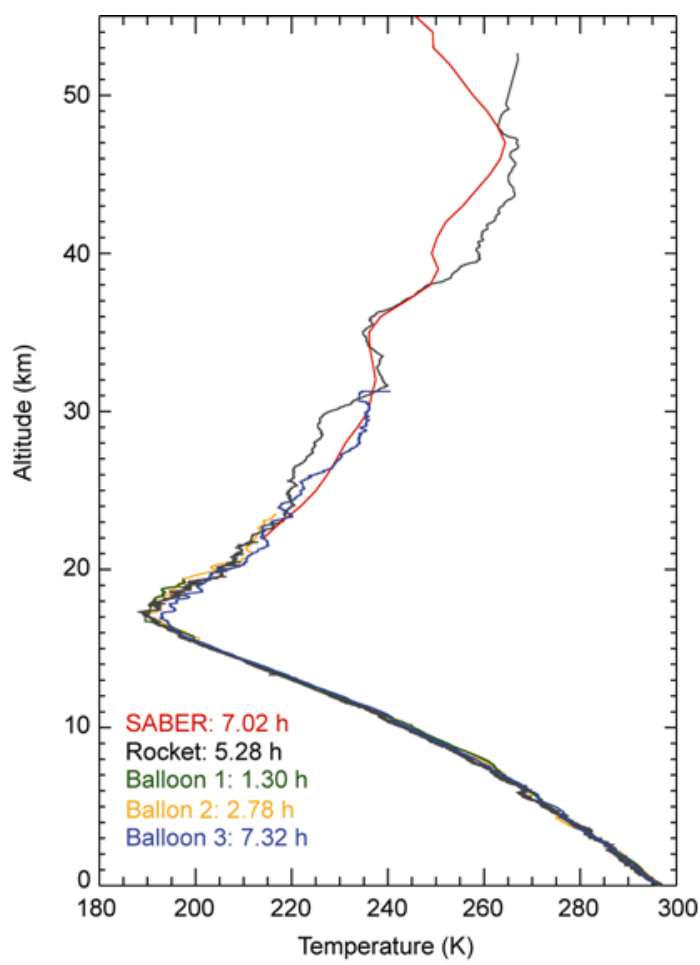

Figure 1 Temperature recorded by the rocket, balloons and SABER. 
a shorter time difference than for the other two balloons. Therefore, the temperature profile recorded by the third balloon is well consistent with the SABER observations.

Figure 2 compares temperatures recorded by the rocket and taken from MSIS00. Figure 2(a) shows that the temperature profile observed by the rocket and that given by the model are basically consistent, and an understandable exception is the altitude of the tropopause detected by the rocket being $2 \mathrm{~km}$ higher than that modeled. Because the rocket measurement is specific to a special location, the rocket records high-resolution data. However, MSIS00 only estimates the average structure and distribution of atmos-

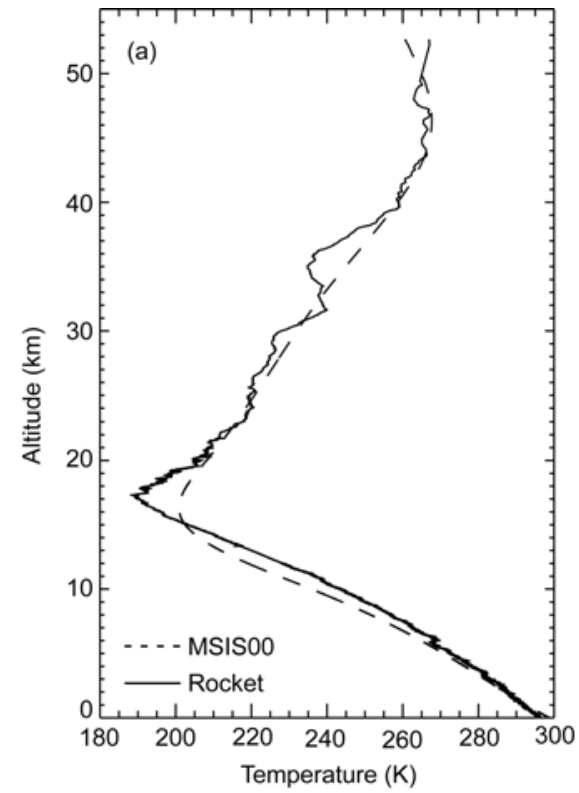

pheric parameters with altitude. Therefore, it is reasonable for the rocket observation and model result to have a $2 \mathrm{~km}$ offset for the tropopause position, and the rocket temperature is believable. Figure 2(b) shows the temperature difference between the rocket and MSIS00 data; the maximum difference of $13.7 \mathrm{~K}$ is at $17.3 \mathrm{~km}$.

Figure 3 shows the wind recorded by the rocket and balloons; the left plot gives the variation in wind speed with altitude and the right plot the variation in wind direction with altitude. In the co-spanned height range, variations in wind speed and wind direction observed by the rocket and balloons are consistent, although there is some difference in

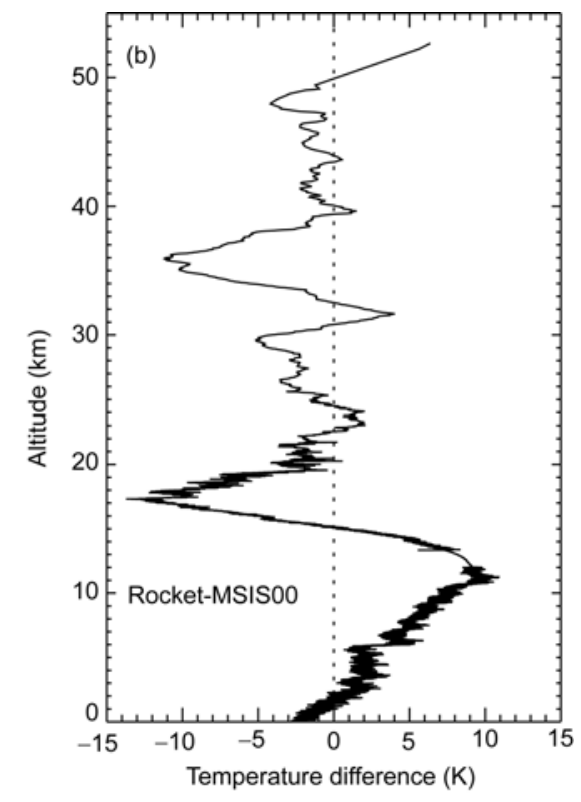

Figure 2 Temperature recorded by the rocket and modeled by MSIS00. (a) Rocket temperature (solid line) and MSIS00 temperature (dashed line); (b) the temperature difference between rocket detection and MSIS00 model (solid line), the dotted line represents 0 difference.
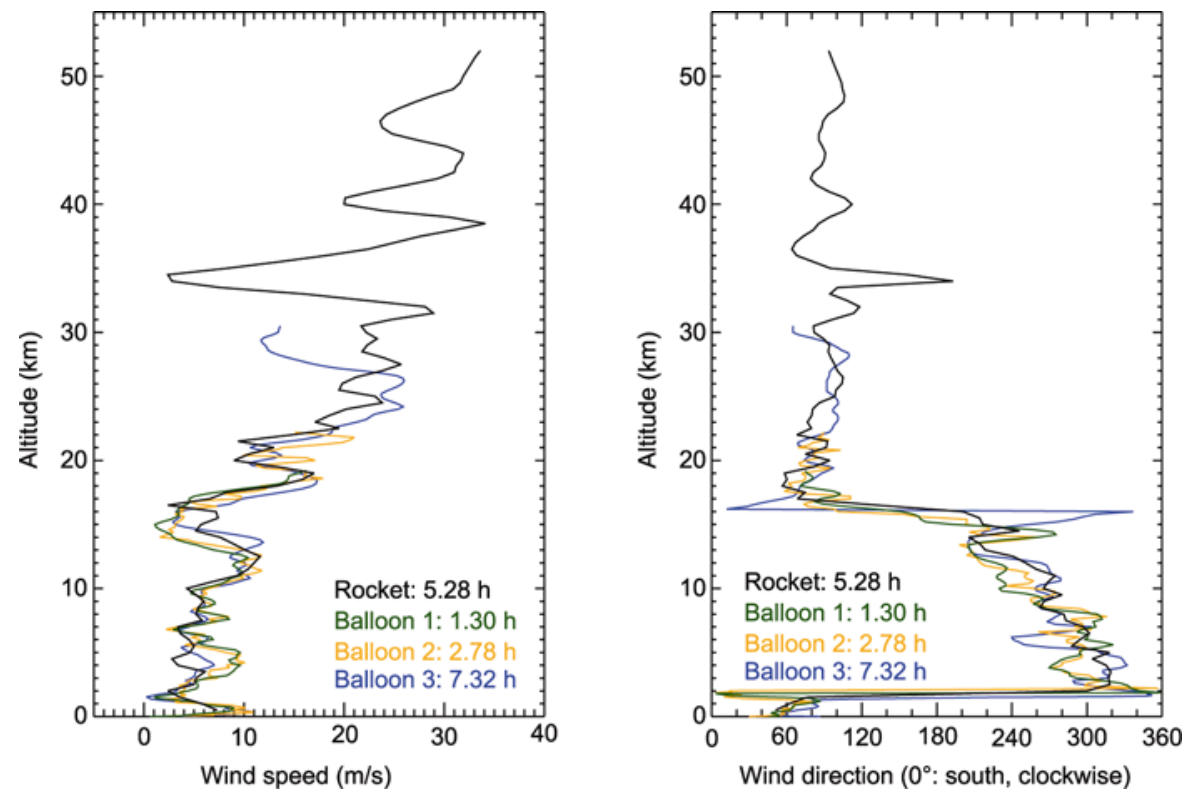

Figure 3 Wind recorded by the rocket and balloons. 
the magnitude. This result is reasonable. Because different instruments measured the atmosphere in different periods, there are differences in the recorded wind; however, because the wind in the height range of $0-52 \mathrm{~km}$ did not change greatly at the time-scale in question (the entire measurement period), the trends in wind variation are similar. Figure 4 compares the wind recorded by the rocket and taken from HWM07. As shown in Figure 4(a) and (c), eastward winds observed by the rocket and simulated by the model have consistent variations at $2-22 \mathrm{~km}$, but have distinct differences above $22 \mathrm{~km}$. Northward winds observed by the rocket and simulated by the model have similar variation trends, and the modeled wind falls into the middle of the range of rocket observations. Therefore, the rocket's
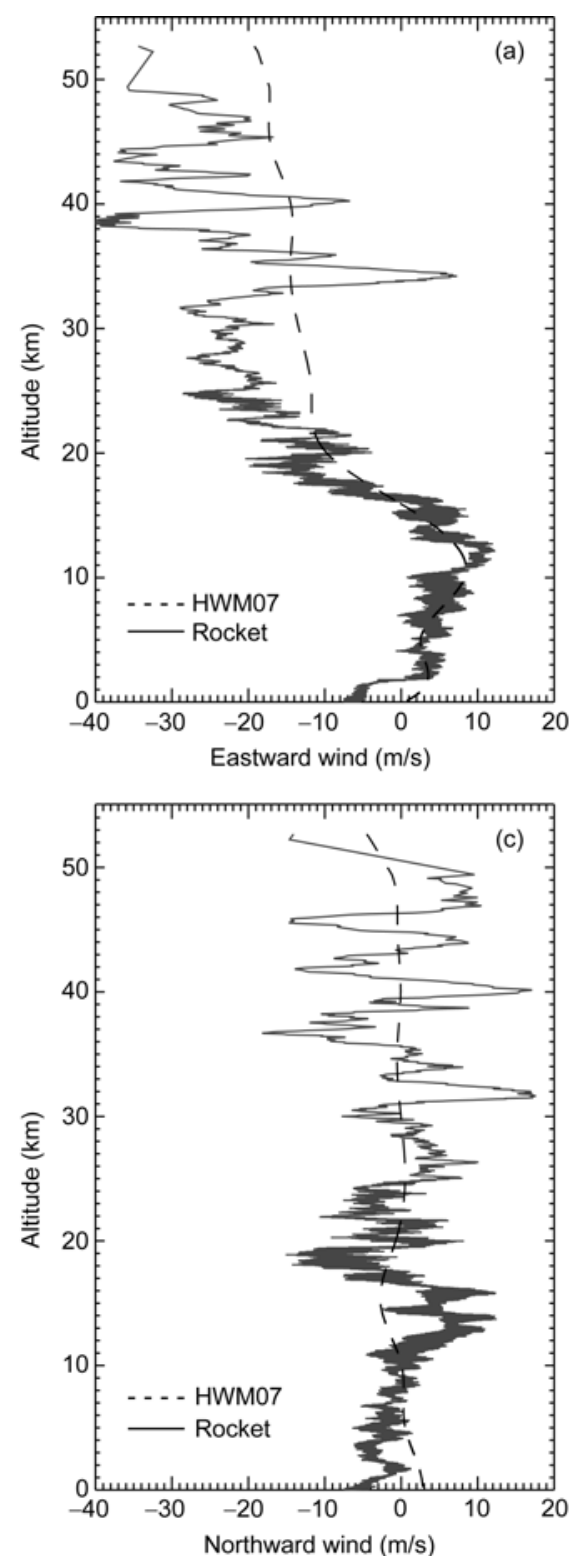

observation corresponds to the model result. Figure 4(b) and (d) show the wind difference between the rocket observation and modeling. The maximum difference in the speed of the eastward wind $(26.1 \mathrm{~m} / \mathrm{s})$ is at $38.6 \mathrm{~km}$, and the maximum difference in the speed of the northward wind (17.9 $\mathrm{m} / \mathrm{s}$ ) is at $31.6 \mathrm{~km}$.

The above comparisons show that the first meteorological rocket of the Meridian Space Weather Monitoring Project and its supportive balloons provided highly reliable data. The Hainan rocket launch site is one of only a few sites at low latitude, and it is close to the Wenchang space facility of China. Therefore, this rocket launch site can be used to advance scientific research, test technology and obtain information on the space environment.
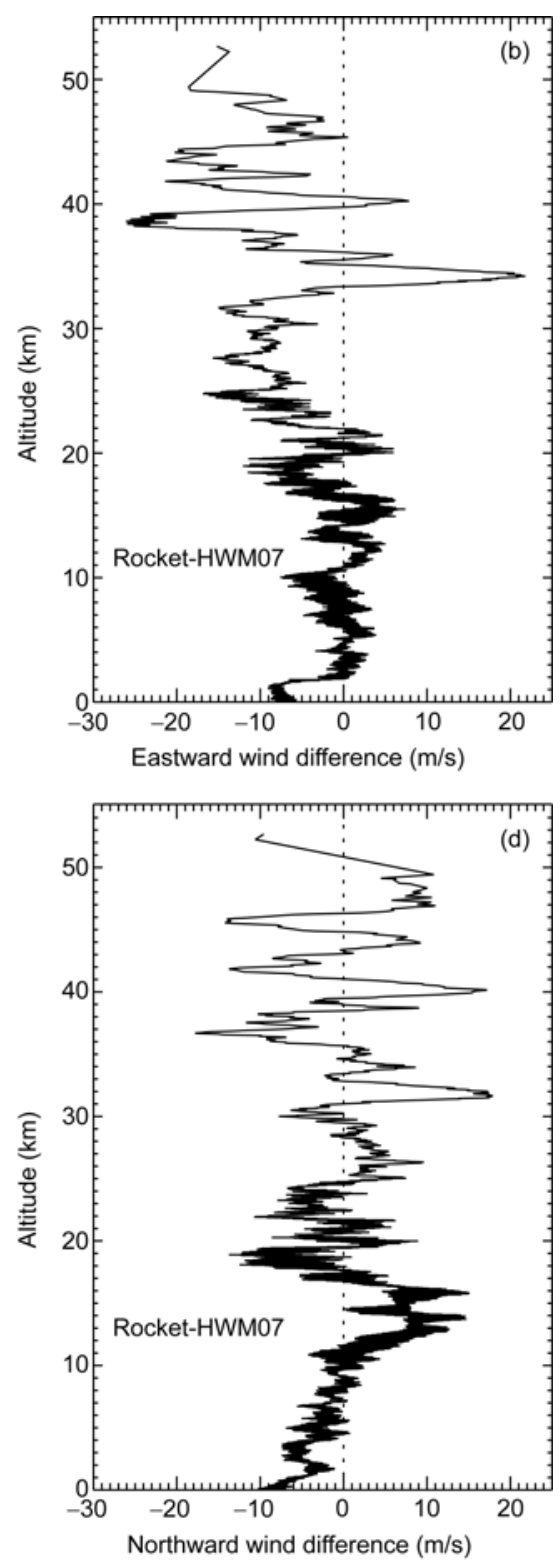

Figure 4 Wind recorded by the rocket detection and modeled by HWM07. (a) The eastward wind detected by rocket (solid line) and the eastward wind from HWM07 (dashed line); (b) eastward wind difference between rocket detection and HWM07 model (solid line), the dotted line represents 0 difference; (c) the northward wind detected by rocket (solid line) and the northward wind from HWM07 (dashed line); (d) northward wind difference between rocket detection and HWM07 (solid line), the dotted line represents 0 difference. 


\subsection{Wind shear and gravity waves}

Wind shear refers to any change in wind speed and/or direction over a relatively short distance in the atmosphere. Wind shear is generally classified into two components: vertical and horizontal wind shear. The horizontal wind shear can be broken into two components: wind shear of horizontal wind in the horizontal direction and wind shear of horizontal wind in the vertical direction. In the real atmosphere, wind shear may be of one type, two types or all types.

In this paper, we focus on the wind shear of horizontal wind in the vertical direction (referred to as wind shear in the following). The formula for calculating the intensity of wind shear is

$$
\frac{\mathrm{d} U}{\mathrm{~d} z}=\sqrt{\left(\frac{\mathrm{d} u}{\mathrm{~d} z}\right)^{2}+\left(\frac{\mathrm{d} v}{\mathrm{~d} z}\right)^{2}} .
$$

Here, $u$ and $v$ are the speeds of eastward and northward wind, respectively, and $z$ is the altitude. The analysis results are shown in Figure 5.

Figure 5 shows that the intensity of wind shear reaches $13 \times 10^{-3} \mathrm{~s}^{-1}$ at the altitude of the tropopause jet (Figure 3 ). There is strong wind shear between 30 and $50 \mathrm{~km}$, and the maximum wind shear is at $40 \mathrm{~km}$. Figure 3 also shows a larger variation in wind in the height range of $30-50 \mathrm{~km}$.

Significant variations in wind and wind shear at 30-50 $\mathrm{km}$ are mostly driven by the atmospheric jet and waves on different scales, especially by gravity waves [1]. The vertical spectrum of gravity waves is further studied using the wind data recorded by the rocket. The method employed to

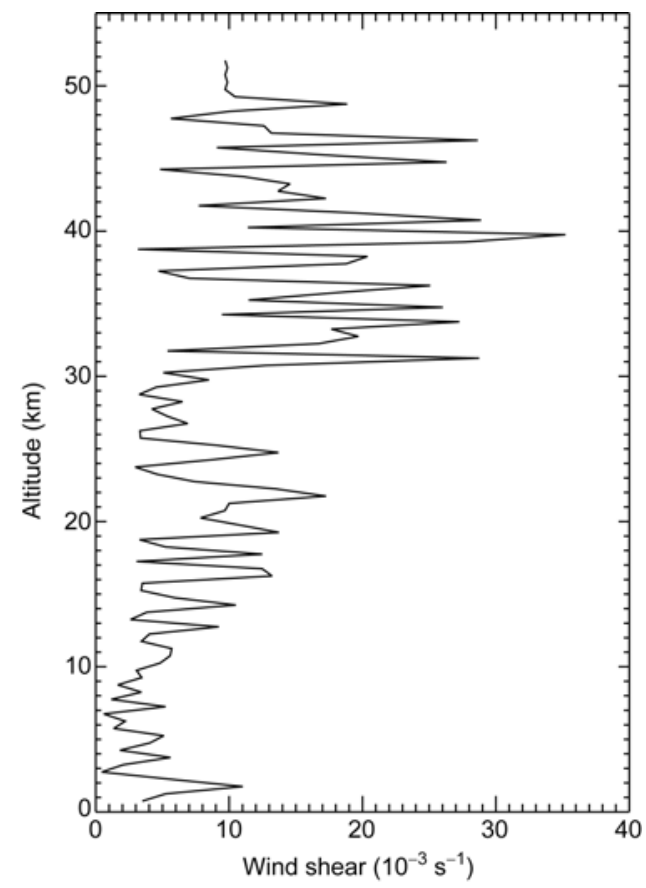

Figure 5 Wind shear derived from rocket measurements. obtain gravity waves is to filter out the waves with a vertical wavenumber less than $0.03 \mathrm{~km}^{-1}$, and then to calculate the vertical spectrum of gravity waves using a Lomb-Scargle periodogram $[1,16,17]$. Figure 6 shows that the strongest gravity wave $(4.09 \mathrm{~m} / \mathrm{s})$ has a vertical wavelength of $3.2 \mathrm{~km}$, and the second strong wave $(4.04 \mathrm{~m} / \mathrm{s})$ has a vertical wavelength of $14.7 \mathrm{~km}$.

\subsection{Analysis of atmospheric stability}

The Richardson number [18] is a dimensionless ratio of the buoyant suppression of turbulence to shear generation of turbulence and is usually used in studying the atmospheric stability of stratified flow of multilayer systems; for example, in determining when unstable flows become or remain turbulent. The formula for the Richardson number is

$$
R i=\frac{N^{2}}{\left(\frac{\mathrm{d} u}{\mathrm{~d} z}\right)^{2}+\left(\frac{\mathrm{d} v}{\mathrm{~d} z}\right)^{2}} .
$$

Here, $N$ is atmospheric buoyancy, and $\mathrm{d} u / \mathrm{d} z$ and $\mathrm{d} v / \mathrm{d} z$ are the derivatives of $u$ and $v$ with respect to the vertical direction (z). The square of atmospheric buoyancy is

$$
N^{2}=\frac{g}{T}\left(\frac{d T}{d z}+\frac{g}{c_{\mathrm{p}}}\right) .
$$

Here, $g$ is gravitational acceleration, $T$ is the atmospheric temperature, $c_{\mathrm{p}}$ is the specific heat at constant pressure, and $\mathrm{g} / c_{\mathrm{p}}=9.8 \mathrm{~K} \mathrm{~km}^{-1}$ is the adiabatic lapse rate of the dry atmosphere.

In theory, laminar flow changes to turbulent flow when $R i<0.25$, at which point there is shear instability $[6,19,20]$. The square of atmospheric buoyancy is another criterion; $N^{2}<0$ indicates an unstable atmosphere and $N^{2}>0$ a stable atmosphere [21,22].

The wind data recorded by the rocket are used to investigate the atmospheric stability over the launch site. Figure 7 shows the Richardson number calculated from the rocket wind data; the left plot gives all values (including the maximum) of the Richardson number from ground to a

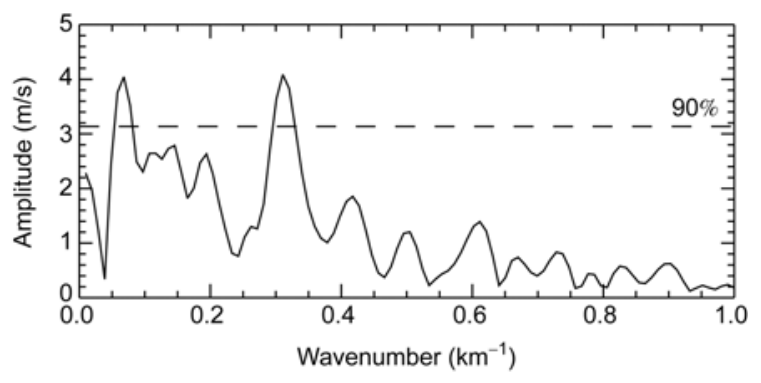

Figure 6 Gravity waves derived from rocket measurements. 
height of $52 \mathrm{~km}$ and the right plot gives only the Richardson number in the range $0-1$, with the dashed line indicating the position where the Richardson number is equal to 0.25 . Figure 8 presents the square of buoyancy calculated from rocket wind data. From Figure 7, we see that all Richardson numbers are greater than 0.25 in the height range of $0-52$ $\mathrm{km}$, which means that that region's atmosphere is stable. Moreover, buoyancy has positive values, which also supports the conclusion that the atmosphere from the ground to a height of $52 \mathrm{~km}$ is stable.
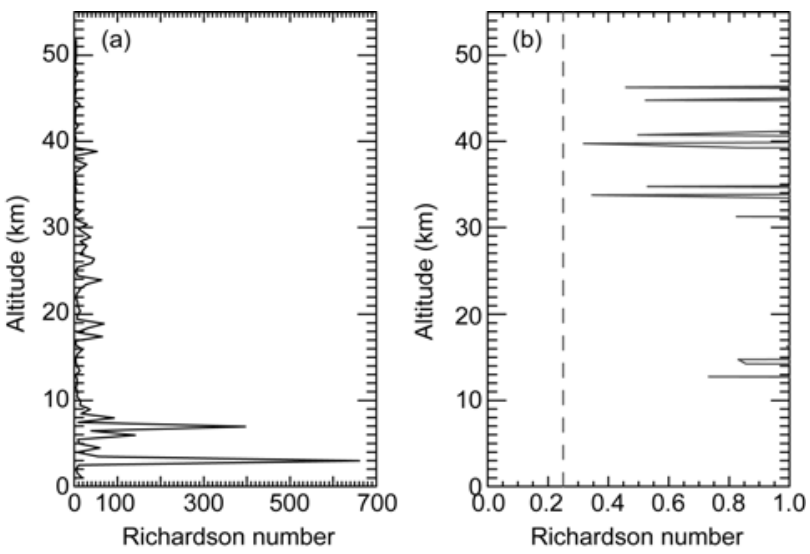

Figure 7 The vertical variation of Richardson number. (a) The Richardson number within 0-700; (b) the Richardson number within 0-1. The dashed line indicates the position where the Richardson number is equal to 0.25

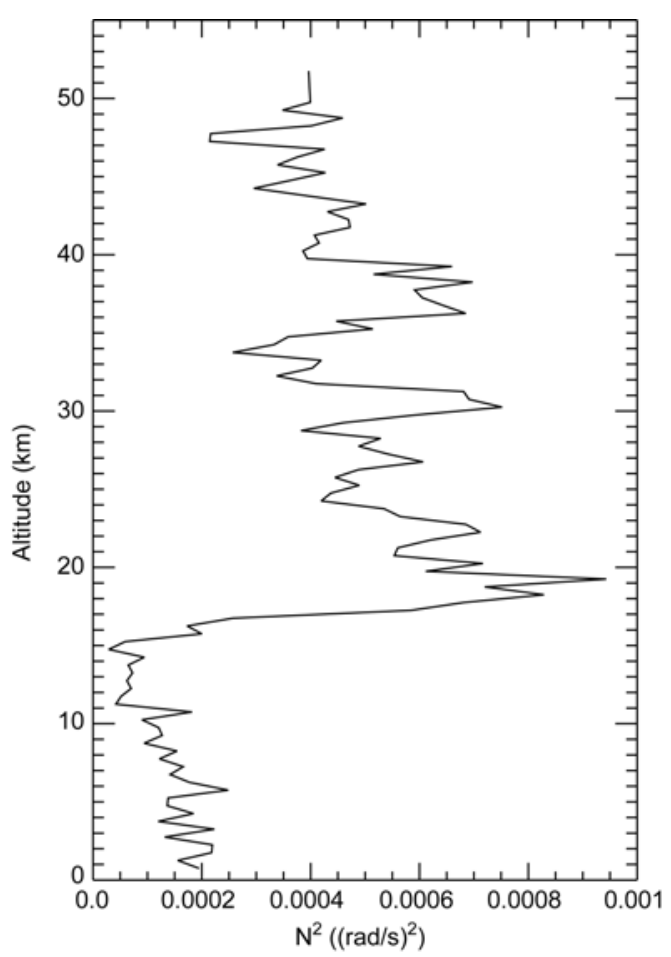

Figure 8 The vertical variation of square of buoyancy frequency.

\section{Summary}

This paper presents the variations and distributions of the temperature and wind at low latitude $\left(19.5^{\circ} \mathrm{N}\right)$ recorded by the first meteorological rocket of the Meridian Space Weather Monitoring Project and its three supportive balloons, which were launched at the Hainan rocket launching site on June 3, 2010. The results are then compared with observations made by the SABER/TIMED satellite and model simulations of MSIS00 and HWM07. Wind shear, gravity waves and atmospheric stability are also studied using the rocket wind data. There are four findings.

(1) The temperature profiles observed by the rocket and balloons are well consistent in the common height range, and the tropopause over the launch site was found to be at an altitude of $\sim 17 \mathrm{~km}$. The rocket, balloon and SABER/ TIMED measurements show similar temperature variations, although the values differ because of the slightly different measurement periods. Because the third balloon has the closest measurement period to that of SABER/TIMED, its temperature field is the most consistent with that of SABER.

(2) Comparison of the temperature recorded by the rocket with that simulated by MSIS00 shows that the trends of the temperature variation are similar and there is a difference in the tropopause position of $2 \mathrm{~km}$ (at $17 \mathrm{~km}$ according to rocket observations and at $15 \mathrm{~km}$ according to the model). The wind recorded by the rocket wind is consistent with the HWM07 simulation.

(3) The maximum wind shear is at $30-50 \mathrm{~km}$, and the second maximum is around the tropopause jet. The vertical spectrum of gravity waves shows that the dominant gravity wave has a wavelength of $3.2 \mathrm{~km}$, and wave with $14.7 \mathrm{~km}$ vertical wavelength also has large amplitude.

(4) The Richardson number and square of buoyancy were used to determine the atmospheric stability over the rocket launch site. The results show that the atmosphere from the ground to a height of $52 \mathrm{~km}$ is basically stable.

We give special thanks to Prof. Ma Ruiping for his kindly help. We acknowledge the use of data from the Chinese Meridian Project. This work was supported by the National Natural Science Foundation of China (40804037, 40890165 and 40921063), the Chinese Meridian Project, and the Specialized Research Fund for State Key Laboratories.

1 Ma R P. Wind and wind shear observed by ZN-1 Rocket at Hainan. Chin J Space Sci, 1997, 17: 70-74

2 Reed R J. Zonal wind behavior in the equatorial stratosphere and lower mesosphere. J Geophys Res, 1966, 71: 4223-4233

3 Sasi M N, Krishna Murthy B V, Geetha R, et al. A study of equatorial wave characteristics using rockets, balloons, lidar and radar. Adv Space Res, 2003, 32: 813-818

4 Antonita T M, Geetha R, Karanam K K, et al. A quantitative study on the role of gravity waves in driving the tropical Stratospheric Semiannual Oscillation. J Geophys Res, 2007, 112: doi: 10.1029/ 2006JD008250 
5 Wüst S, Bittner M. Gravity wave reflection: Case study based on rocket data. J Atmos Solar-Terr Phys, 2008, 70: 742-755

$6 \mathrm{Wu}$ Y F, Widdel H U. Saturated gravity wave spectrum in the polar lower thermosphere observed by foil chaff during campaign "Sosium 88". J Atmos Sci, 1992, 49: 1781-1789

7 Schöch A, Baumgarten G, Fritts D C, et al. Gravity waves in the troposphere and stratosphere during the MaCWAVE/MIDAS summer rocket program. Geophys Res Lett, 2004, 31, doi: 10.1029/2004GL019837

$8 \mathrm{Xu} \mathrm{J}$, She C Y, Yuan W, et al. Comparison between the temperature measurements by TIMED/SABER and lidar in the midlatitude. J Geophys Res, 2006, 111: doi: 10.1029/2005JA011439

$9 \mathrm{Xu} \mathrm{J}$, Smith A K, Liu H L, et al. Seasonal and quasi-biennial variations in the migrating diurnal tide observed by Thermosphere, Ionosphere, Mesosphere, Energetics and Dynamics (TIMED). J Geophys Res, 2009, 114, doi: 10.1029/2008JD011298

10 García-Comas M, López-Puertas M, Marshall B T, et al. Errors in Sounding of the Atmosphere using Broadband Emission Radiometry (SABER) kinetic temperature caused by non-local-thermodynamicequilibrium model parameters. J Geophys Res, 2008, 113, doi: 10.1029/2008JD010105

11 Huang F T, Mayr H G, Reber C A, et al. Stratospheric and mesospheric temperature variations for the quasi-biennial and semiannual (QBO and SAO) oscillations based on measurements from SABER (TIMED) and MLS (UARS). Ann Geophys, 2006, 24: 2131-2149

12 Remsberg E E, Marshall B T, Garcia-Comas M, et al. Assessment of the quality of the Version 1.07 temperature-versus-pressure profiles of the middle atmosphere from TIMED/SABER. J Geophys Res, 2008, 113, doi: 10.1029/ 2008JD010013
13 Zhu X, Yee J H, Talaat E R, et al. Diagnostic analysis of tidal winds and the Eliassen-Palm flux divergence in the mesosphere and lower thermosphere from TIMED/SABER temperatures. J Atmos Sci, 2008, 65: 3840-3859

14 Picone J M, Hedin A E, Drob D P, et al. NRLMSISE-00 empirical model of the atmosphere: Statistical comparisons and scientific issues. J Geophys Res, 2002, 107, doi: 10.1029/2002JA009430

15 Drob D P, Emmert J T, Crowley G, et al. An empirical model of the Earth's horizontal wind fields: HWM07. J Geophys Res, 2008, 113, doi: 10.1029/2008JA013668

16 Lomb N R. Least-squares frequency analysis of unequally spaced data. Astrophys Space Sci, 1976, 39: 447-462

17 Scargle J D. Studies in astronomical time series analysis. II. Statistical aspects of spectral analysis of unevenly spaced data. Astrophys J, 1982, 263: 835-853

18 Richardson L F. The supply of energy from and to atmospheric eddies. Proc R Soc Lond A, 1920, 67: 354-373

19 Kundu P, Beardsley R. Evidence of a critical Richardson number in moored measurements during the upwelling season off northern California. J Geophys Res, 1991, 96: 4855-4868

20 Lyons R, Panofsky H A, Wollaston S. The critical Richardson number and its implications for forecast problems. J Appl Meteorol, 1964, 3: $136-142$

21 Tsuda T, VanZandt T E, Mizumoto M, et al. Spectral analysis of temperature and Brunt-Väisälä frequency fluctuations observed by Radiosondes. J Geophys Res, 1991, 96: 17265-17278

$22 \mathrm{Wu} \mathrm{Y,} \mathrm{Xu} \mathrm{J,} \mathrm{Yuan} \mathrm{W,} \mathrm{et} \mathrm{al.} \mathrm{Spectral} \mathrm{analysis} \mathrm{of} \mathrm{10-m} \mathrm{resolution}$ temperature profiles from balloon soundings over Beijing. Ann Geophys, 2006, 24: 1801-1808

Open Access This article is distributed under the terms of the Creative Commons Attribution License which permits any use, distribution, and reproduction in any medium, provided the original author(s) and source are credited. 